\title{
Lead Logistics Provider and Its Effect on Supply Chain Alliances - A Case Study on Taiwan Motor Industry
}

\author{
Jheng-Dan Huang \\ Department of Industrial Engineering and Management, Yuan Ze University, Chungli, Taiwan \\ Michael H. Hu \\ Department of Industrial Engineering and Management, Yuan Ze University, Chungli, Taiwan
}

H. M. Wee*

Department of Industrial and Systems Engineering, Chung Yuan Christian University, Chungli, Taiwan E-mail:weehm@cycu.edu.tw

\begin{abstract}
The increasing competition due to globalization and e-Business development has stimulated manufacturers to pursue supply chain alliances more aggressively. The primary motivation for this is to minimize overall costs and gain mutual benefits through supplier-manufacturer integration. Supply chain alliance is one of the key strategic co-operations adopted by manufacturers to simultaneously reduce costs and improve service. The advancement of supply chain alliance is moving from a Third-Party Logistics System to a Lead Logistics Provider Management System. The Lead Logistics Provider plays the role of logistics manager who lead the logistics operations across the entire supply chain with the ability to provide superior expertise in transportation services, warehousing capabilities, information technology, and materials replenishment among the other logistics activities. A Lead Logistics Provider system framework is composed of three components that include Resources Management, Information Central System, and Logistics Synchronization. This study presents a case of a Taiwanese automotive supply chain illustrating the application of supply chain alliances via the Lead Logistics Provider system. Significant improvement on inventory costs and improvement on the transportation performance is reported resulting from the application of this system. This scheme also showed enhanced service quality that creates business opportunities among the supply chain partners.
\end{abstract}

Keywords: Lead logistics provider, supply chain alliances, third-party logistics, automotive industry

\section{Introduction}

The rapid globalization and development of ebusiness practices have led manufacturers to pursue supply chain alliances. The primary reason behind this is to minimize the overall costs while satisfying quality requirements through supplier-manufacturer integration. Outsourcing logistics through a third party logistics (3PL) service provider is one of the key strategies in achieving reduced supply chain costs and improved service leadership.
The supply chain management of Taiwanese automotive industry is experiencing significant changes during the past decade. The leading firms such as Ford, Nissan, and Mitsubishi are all seeking for upstream and downstream suppliers to build close partnership under a globally competitive environment. Their aim is to effectively manage their suppliers throughout the entire supply chain to achieve faster delivery, less production lead-time, reduced cost, and increased quality (Hu et al., 2008).

*Corresponding Author 
Hence they seek for strategic suppliers that would help strengthen their competitiveness to deal with the competition in the supply chain environment and achieve efficient customer service to survive and create win-win prospects.

A supply chain network involves different processes and activities from upstream towards the downstream linkages to produce products and services desired by the consumers (Xiao et al., 2009). From the order fulfillment process perspective, a supply chain includes all activities for transforming raw materials into end-products. Relating this to the automobile manufacturing industry, the supply chain network for this consists of the raw materials providers, auto parts suppliers, automobile assembly plant, distributors, retailers, and customers.

In the early prevalent vertical integration era, like the automotive industry, a manufacturer attempts to own or buy all the upstream and downstream supply chain players to gain total channel control (Williams et al., 2002). Aiming also for costs reduction, many firms started to focus on its core competencies by eliminating non-core units or operations and partnering with other firms that have the capability to provide the same quality but with more cost-effective service. Supply chain management is a horizontal integration approach that engages a set of independent firms to form a chain or network to take advantage of cost reductions and profitability opportunities. The structure of a supply chain is depicted in Figure 1.

An effective supply chain is usually characterized by its flexibility towards its operations which is commonly enabled through integrated information technology. Independent firms throughout the supply chain develop and maintain integration through

Figure 1. The Structure of supply chain management

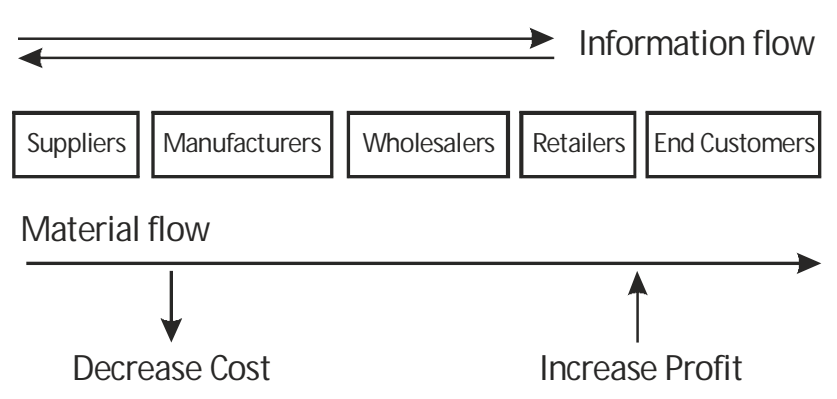

various strategic alliances with their partners to allow quick response capability which greatly enhance the chain performance. Strategic alliances enable supply chain players to contribute their individual strengths and work cooperatively together to reduce non-valueadding activities that could lead to the performance improvement of the overall supply chain (Whipple, 2000). The strategic alliance relationships are usually developed and players remain committed based on the mutual benefits in which they have the basic right and obligation to undertake joint risks and shared profits (Lewis, 1990). The ultimate goal of any strategic alliance is to achieve long-term success for all players by maintaining a win-win relationship.

This study aims to demonstrate the effectiveness of a supply chain alliance, particularly the application of a Lead Logistics Provider (LLP) in the automotive industry supply chain that helped reduce the logistics costs and improve logistics flexibility enhancing the entire chain competitiveness. The rest of the paper is outlined as follows. Section 2 discusses the alliances in the supply chain structure of different firms in the industry. Section 3 narrows the supply chain scope into the LLP system. Section 4 demonstrates the application of the LLP system in the automotive industry and the success factors in the development of the LLP system is discussed in Section 5. Lastly, conclusions are summarized in the last section.

\section{The LLP development in supply chain management}

The Lead Logistics Provider industry had started dating back in 1980. Since then, the LLP system has been extensively adopted by many kinds of industries over the years. LLP leads the logistics operations across an entire supply chain focusing on the logistical service operations and information technology.

In the past decade, many researchers from the academia and industry studied on enhancing the supply chain management performance, as well as the advancement through strategic alliances. The most renowned LLP case is the logistics partnership between MC Trans International (McTI), a Japanese 3PL provider, and the MAZDA automotive company. McTI (2004) provided a complete inbound and outbound logistics solution for MAZDA by coordinating with all the automotive suppliers to deliver auto-parts to MAZDA factories in Hiroshima, 
and distributing the assembled cars to the dealers. Logistics information sharing is performed through information technology integration between McTI and MAZDA. McTI receives order information from MAZDA by electronic data interchange (EDI) and manages just-in-time (JIT) parts delivery with more than 300 upstream suppliers.

LLPs are progressively being considered as strategic, complementary players which are actively building strategic partnerships with their supply chain players. Coyle et al. (1996) viewed logistic alliances as outsourcing evolving over a continuum characterizing with an increasing use of external logistics services. Several outsourcing strategies identified in the industry are: outsourcing individual activities, outsourcing multiple activities, outsourcing all activities, and single source logistics services outsourcing. The initial outsourcing strategy is limited to individual activities such as transportation and warehousing, while the logistics function coordination is operated in-house. On the other hand, single source logistics outsourcing represents strategic logistics alliances between firms and logistics providers.

Bhatnagar and Viswanathan (2000) suggested concentrating logistics alliances on a relationship continuum rather than a series of single transactions. Different from simple logistics outsourcing where cost is an overriding factor, a strategic logistics alliance is a special business contract in which the logistics provider is treated as an extended organization. In order to be classified as a strategic alliance, cost benefits from the logistics relationship must be ensured to both parties and the competence of each party must be utilized to enhance the competitive position of both firms. In practice, the logistics relationship is facilitated by supply chain mechanisms such as information technology integration and account management (Hoek, 2000). The former is an essential infrastructure investment to enable information exchange and supply chain collaboration. The latter is a cross-company interface mechanism in which an account manager coordinates all services offered by the logistics provider to a particular customer and serves as a single contact window for that customer.

LLP updates their information technology and equipment to increase customer-satisfaction capability. One industry example is the Ryder Dedicated Logistics Company who cooperated with the Simmons Mattress Manufacturing company wherein the former sent one logistic manager to work in the latter. When any order is acquired, the manager will plan the best transport procedure and route for sending the mattresses to customers, using special software. The information is then sent to each floor of the factory to ensure the best quality, the right quantity, and the correct order time for the customer. This kind of partnership successfully reduced the inhouse mattress stock by 20,000-50,000 mattresses. (Andel , 1995)

LLP can also provide a Quick Response System (QR) to quickly replenishment the stocks to achieve flexible service and provide the customers with variety of services. Sonic Air provides QR to any place in its facilities where parts are needed. Sonic Air controls 67 storage facilities and uses professional software to control the stock level. When receiving an order, the order is keyed-in into the Sonic Air system. The software will then determine the best allocation method and then perform the shipment following the provided method. Owing to high efficiency and quick replenishment service, the customer's inventory can be reduced thereby producing reduction in cost. Sonic Air also received high profits because of the customers' willingness to pay for high level service (Andel , 1995).

In 1988, the American National Council of Logistics Management first used the term "third party providers" which offer logistics services in transportation, terminal activities, warehousing, forwarding, packaging, logistics postponement, distribution, information exchange, etc. (Bask, 2001). The 3PL provider engages both suppliers and customers in the supply chain to form strategic logistical partnerships. Bolumole (2001) indicated that the success of the logistics partnership is dependent on the 3PL provider's capability to meet the performance requirements set by the buying firms. One of the most common ways to implement logistics alliance is to adopt a business process reengineering approach along the supply chain to cut across organizational barriers.

Researches were also carried out in the automotive industry in which manufacturers traditionally maintain a variety of parallel subcontractors for inbound and outbound logistics. The development of logistics alliances in the automotive industry began in 1980. Andel (1995) 
surveyed the logistics partnership between GATX and General Motors and presented the benefits obtained through lower transportation costs and better delivery service. Another US automotive giant, Ford Motors, established logistics alliances with Rider (2004) to provide JIT automotive parts delivery from its spun-off supplier - Visteon. Significant savings in transportation cost was reported as a result from Rider's logistics service.

The LLP practice forced the automotive manufacturer to develop, implement, and operate a centralized logistics network for Ford. Ford Motor Company, being one of the world's largest automotive manufacturers, worked with Penske on logistics improvement initiatives. Being its LLP, Penske's logistics development team of associates were trained in logistics practices and worked closely with Ford to streamline operations to create and maintain a more centralized logistics network. By February 2001, Penske had completely transitioned Ford's logistics operations into a centralized network design. More than 700 inbound and 500 outbound trailers now move to and from Ford's ODCs per day with most loads carrying at 95 percent capacity. Shipments are consolidated at the ODC and previously unused cross-docking space had been utilized. Fourteen million pounds of freight are cross-docked each day resulting in an inventory reduction of 15 percent. Together they uncovered several areas for real cost savings as a result from reducing inbound carrier discrepancies, eliminating unnecessary premium costs, and reducing shipment overages. In addition, Penske implemented accountability procedures and advanced logistics management technologies to gain more visibility of its overall supply network.

\section{Lead logistics provider (LLP) system in automotive supply chain}

A Lead Logistics Provider (LLP) is any logistics company that has expertise in optimizing material movement in a supply chain. This task is also considered as one of the sub-process of the Synchronized Material Flow (SMF) wherein all inbound and outbound transportation of materials are managed to ensure the delivery of material following the principle of more frequent replenishments in smaller quantities within the specified window time. This type of companies lead the logistics operations across the entire supply chain with the ability to provide superior expertise in transportation services, warehousing capabilities, information technology, replenishment, and supply of materials among other logistics activities. Moreover, they have to continuously strive for efficiency and process improvements. The strategy for Lead Logistics Provider is derived from the Ford Production System (2005).

Whenever an Original Equipment Manufacturer (OEM) implements a logistics outsourcing project, it is suggested to have a single contract and a single computer interface so as to have a single point of contact. However, given the way logistics organizations perform today, it is difficult to find a logistics service provider (LSP) that has the expertise and competence to manage all operations. In order to attend to this necessity, LSP contracts are necessary to provide a single point of contact to its customers.

The development of logistics alliances is moving from 3PL to fourth-party logistics (4PL). The 3PL uses an outside company to perform all or part of the firm's logistics activities. However, the 4PL is a supply chain service provider that participates in supply chain coordination rather than in operational services (Hoek and Chong, 2001). It is highly information-based and it coordinates multiple asset-based logistics providers on behalf of its clients. Armbruster (2002) argued a better way to describe the $4 \mathrm{PL}$ as a lead logistics provider (LLP) which coordinates the work of 3PL providers and other transportation providers. The $4 \mathrm{PL}$ role is similar to that of a general contractor for a construction project, who manages constructors, plumbers, electricians, and carpenters. In the logistics field, the general contractor is the 4PL and the subcontractors are the 3PLs, carriers, forwarders, brokers, and other firms. Table 1 compares the three different LSPs.

The lead logistics provider (LLP) or fourth-party logistics (4PL) provider assumes accountability for the management, performance, cost and development of all supply chain functions, transactions, systems and suppliers. The customer receives agreed service levels across the supply chain along with one contact point and one invoice if required.

The emergence of LLP has raised questions and debates such as: Does the LLP simply create another level of bureaucracy? Can the LLP deliver what it 
Table-1. Comparison for different logistics service providers

\begin{tabular}{|l|l|l|l|}
\hline \multicolumn{1}{|c|}{ Item/Description } & \multicolumn{1}{|c|}{ 3PL } & \multicolumn{1}{c|}{ 4PL } & \multicolumn{1}{c|}{ LLP } \\
\hline Scope of services & $\begin{array}{l}\text { Logistics managed model including } \\
\text { transportation, warehousing, inventory } \\
\text { management, and freight forwarding. }\end{array}$ & $\begin{array}{l}\text { Full supply chain services including } \\
\text { 3PL basic functions, Information } \\
\text { Technology services, and Business } \\
\text { Process Management. }\end{array}$ & $\begin{array}{l}\text { Full supply chain services including } \\
\text { Resource management, Information } \\
\text { Central System, and Logistics } \\
\text { synchronization. }\end{array}$ \\
\hline Characteristics of services & $\begin{array}{l}\text { Logistics specialty services focus on } \\
\text { transportation and warehousing } \\
\text { operation. }\end{array}$ & $\begin{array}{l}\text { upply chain alliance leading, single- } \\
\text { point-of- contact integrated service. }\end{array}$ & $\begin{array}{l}\text { Managing internal and external } \\
\text { logistics to synchronize material flow. }\end{array}$ \\
\hline Facilities \& warehouses & Possession of facilities and warehouses. & Outsourcing & Outsourcing \\
\hline Fleet & Possession of fleet & Outsourcing & Outsourcing \\
\hline Information Technology service & Not applicable & Develop and provide IT services & Develop and provide IT \\
\hline
\end{tabular}

promises? Will the potential savings impact the service? These questions can be answered by successful applications of the LLP solution. Notel Network outsourced its outbound logistics to Kuehne \& Nagel Lead Logistics and achieved a more than $10 \%$ of its annual global logistics services (Armbruster, 2002). UPS Logistics provided a complete 4PL business solution to fulfill its client's expectations (Hoek and Chong, 2001). Bowman (1995) surveyed the applications of LLP by Kodak, 3M, DOW Chemical, Time Hwa-Na, Sears Roebuck, etc. with solid logistics savings and transportation service improvement. Simhan (2003) reported about $75 \%$ of the Fortune 100 companies, and about $45 \%$ of Fortune500 companies have adopted the LLP solution. It is also worth indicating that the above cited LLPs are also strong 3PL providers. This finding is consistent with the top six 4PLs, including Deutsche Post, Federal Express Supply Chain
Services, Menlo Worldwide, Penske Logistics, TNT Logistics, and UPS Supply Chain Solutions (Schwartz, 2003).

Before moving the focus to the LLP applications in the automotive industry, an automotive supply chain is presented as shown in Figure 2. A typical automotive supply chain involves five major players namely: suppliers for parts and components supply, inbound 3PL providers for inbound logistics, manufacturers for vehicle assembly, outbound 3PL providers for vehicle distribution, and retailers for customer contact and vehicle sales. A tremendous amount of parts and components are required to produce a vehicle, hence, both parts purchasing and inbound logistics have important roles in the automotive supply chain. Similarly, physical transportation and distribution of vehicles to various retailers and customers require comprehensive outbound logistics services. Therefore, LLP provides

Figure 2. The automotive supply chain and its LLP system

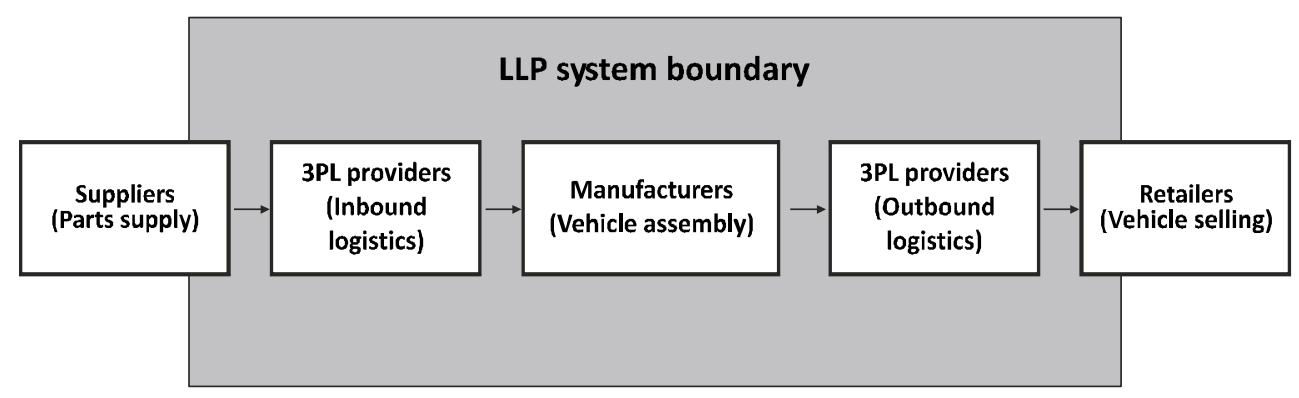


Figure 3. The LLP system framework

\begin{tabular}{|c|c|c|}
\hline \multicolumn{3}{|c|}{ LLP System Framework } \\
\hline $\begin{array}{l}\text { Resource Management } \\
\text { - Logistics vendor } \\
\text { management } \\
\text { - Logistics network and } \\
\text { facility } \\
\text { - Transportation } \\
\text { management } \\
\text { - Account management }\end{array}$ & $\begin{array}{l}\text { Information Central } \\
\text { System } \\
\text { - IT system integration } \\
\text { - Data exchange } \\
\text { standard } \\
\text { - Real time information } \\
\text { sharing and data } \\
\text { tracking } \\
\text { - Logistics decision } \\
\text { support system }\end{array}$ & $\begin{array}{l}\text { Logistics } \\
\text { Synchronization } \\
\text { - usiness and operation } \\
\text { know-how } \\
\text { - Process integration } \\
\text { and management } \\
\text { - Synchronized material } \\
\text { flow } \\
\text { - Performance } \\
\text { management }\end{array}$ \\
\hline
\end{tabular}

an integrated logistics solution that covers both inbound and outbound logistics across all supply chain players.

One of the most successful LLP partnerships in the automotive industry is the logistics alliance between General Motors (GM) and Vector SCM. The latter plays the role of lead logistics manager worldwide for the former, the world's largest vehicle manufacturer. The company is a joint venture between CNF and GM. Vector SCM leverages the extensive supply chain expertise of all of CNF's operating companies along with advanced web-based technologies developed by CNF to produce end-toend visibility of all material and vehicles moving within GM's supply chain (Vector, 2004). Vector SCM's goal is to improve the speed, flexibility, and reliability of GM's global supply chain. GM claimed to achieve a $7.5 \%$ savings in its annual logistics spending in 2001 (Armbruster, 2002). The alliance also improves GM's supply chain visibility through technology. Another automotive giant, Ford Motors, outsourcing its lead logistics management to Rider enables Ford and its first tier supplier, Visteon, to focus on core business activities and achieve significant logistics savings. Volvo Logistics (2004) acts as the LLP for Volvo in coordinating the operations throughout the supply chain-manufacturers, suppliers, careers, warehouse operators, forwarders, brokers, customs agencies, and others.
The role of the LLP is to coordinate the logistics operations of various parties throughout the automotive supply chain. A successful LLP solution can base on the proposed framework shown in Figure 3. The LLP system framework consists of three components: Resource Management (RM), Information Central System (ICS) and Logistics Synchronization (LS). As a logistics coordination expert, the LLP should be able to establish and manage logistics supplier portfolios including vendor sourcing, vendor selection, contract negotiation, logistics and transportation networks, and account management mechanism. The second component, ICS, is an indispensable enabler for a LLP application. The ICS covers the IT system integration across supply chain players, data exchange standard, real-time information sharing, and logistics decision support system. The third component, LS, is the core LLP selection criteria for automotive industry. In order to fulfill synchronized manufacturing requirements, the LLP must have strong business and operation expertise in the automotive industry. Most LLP program depends on a comprehensive business process re-engineering to achieve logistics integration. The synchronized material flow (SMF) process is to manage all inbound materials delivery and outbound product pick-ups for the manufacturer in accordance with the principle of more frequent, smaller-sized batches and within a specified time window. The established ICS is used to share material forecast and 
Figure 4. The LLP system solution model

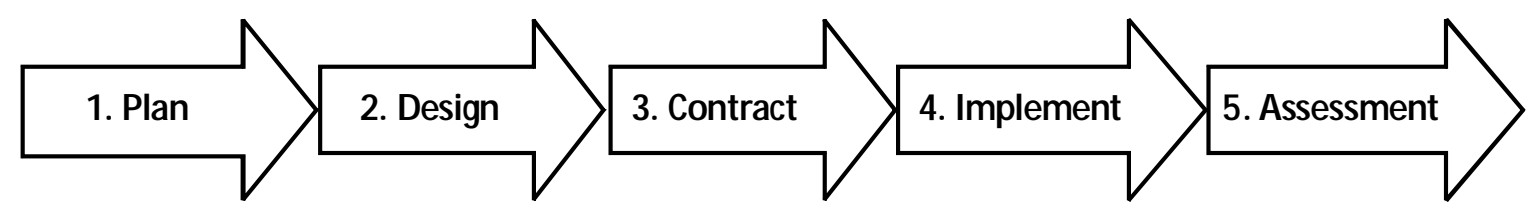

production schedule information, and generate performance measurement reports.

An automotive manufacturer can take alternative approaches to implement a LLP system such as developing an existing 3PL provider to play LLP role, contracting the IT service provider to take over the lead logistics management role, or outsourcing entire logistics operations to a professional LLP. The most common approach is to establish a logistics partnership with professional LLP. An automotive manufacturer can follow the solution model shown in Figure 4 to implement a LLP system.

1. Planning stage: Top executives make the business decisions for implementing the LLP system and appoint a Program Office to develop a preliminary plan.

2. Design stage: The Program Office conducts a LLP vendor sourcing based on pre-defined business requirements. The LLP system framework is used to evaluate vendor's qualification and make vendor selection decision. A LLP project plan is then developed.

3. Contract Establishment stage: The selected LLP works on business contract with the manufacturer to outline Logistics Partnership, Service terms, and Implementation plan. The LLP is also responsible for signing subsequent sub-contracts with other suppliers, 3PL providers, and related logistics providers.

4. Implementation stage: The LLP finalizes logistic management details that includes setting up Material Requirement Planning and Advanced Shipping Notice (ASN) delivery control system, building integrated information system to process daily supplier release and production forecast information, and completing the logistics network design. A pilot implementation of a selected parts and suppliers is conducted to finetune the ICS and LS before a full-scale implementation of LLP system.
5. Assessment stage: The Program Office works with the LLP to access logistics performance and align logistics processes until the desired service requirements are achieved. Finally, a formal review process is started to manage logistics performance and strategic relationships.

\section{LLP case study in automotive supply chain}

To verify the feasibility of the LLP system, this research studies a logistics project via LLP in an automotive supply chain. The project is provided by Taiwan McTI (MC Trans International INC), with the purpose of increasing the productivity of the automotive assembly plant and marketing competition of suppliers and through LLP system.

Ford Motor Company established domestic production plants in Taiwan in 1972. With its continuing efforts on manufacturing excellence and service quality, Ford Motor Taiwan became the third largest automotive manufacturers in the domestic market. In order to face the tough domestic competition and potential foreign threats after Taiwan's WTO accession, Ford Taiwan initiated a supply chain innovation through a LLP to improve their cost leadership in 2005. The objectives of the LLP initiatives are to reduce inventory cost and transportation cost across their supply chain. The LLP solution model presented in Figure 4 was used to carry out the project.

In early 2005, Ford Taiwan established a supply chain management program office to design and implement the LLP solution. In the design stage, the program office conducted a series of LLP solution surveys and benchmark studies to select the best LLP vendor. The vendor selection criteria were based on the capability of providing resource management, information system integration and collaboration, and logistics synchronization for their entire 
automotive supply chain. McTI, - a Japanese LLP solution leader in the automotive supply chain, who was then seeking business expansion in Taiwan, was selected as the LLP partner to Ford Taiwan to provide a lead logistics management service in mid-2005.

In the implementation phase, McTI Taiwan focused on resource management establishment, information system integration, and logistics synchronization. In terms of resource management, McTI has accumulated more than 40 years of logistics service experience in the automotive industry wherein they had operated lead logistics services in over its 30 global locations in 2000. McTI's worldwide network and facility includes logistics centers, global transportation, and domestic distribution. In line with Ford Taiwan's LLP project, McTI Taiwan established a logistics center in July 2005 to support its domestic logistics operations. Assuming the role of coordinating with all automotive suppliers, McTI Taiwan adopts an Account Management mechanism with each contracted supplier across the design, implementation, and assessment phases of the LLP project. It is noted that the backbone of the logistics coordination significantly relies on the construction of an information central system among all players.

McTI Taiwan adopted LOGICOM system (Logicom, 2004) as its lead logistics management system. The LOGICOM system, developed by
LOGICOM Corporation, Japan, is an advanced information and logistics management system for the automotive supply chain. The LOGICOM system structure is shown as Figure 5. The functionality of the LOGICOM system covers a full spectrum of all logistical operations, including warehousing operation, inventory management, transportation management, and order procurement. Based on the data exchange standards outlined by LOGICOM system, McTI Taiwan achieved IT system integration with Ford Taiwan and its suppliers enabling them for real-time information sharing. The LOGICOM system also provides real-time demand forecast, production planning and adjustment, and logistics decision support.

McTI is a Lead Logistics Company who manages the entire process of collecting parts and components from the suppliers and delivering them into Ford Taiwan assembly plant. It applies a MilkRun Process to deliver the suppliers' parts to automotive assembly plant at small quantities and higher frequencies. Figure 6 illustrates the LLP system network (McTI, 2005) developed for Ford Taiwan for part supply and inbound logistics.

With in-depth automotive operation know-how and experience, McTI Taiwan is able to fulfill the production synchronization requirements of Ford Taiwan. The purpose of production synchronization

Figure 5. LOGICOM system structure

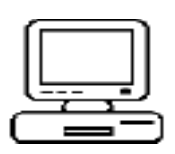

VENDOR
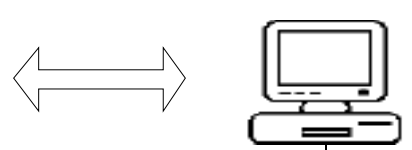

LOGICOM
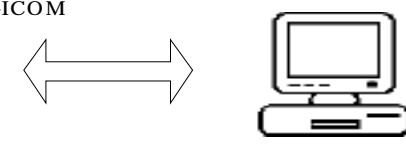

CAR MAKER

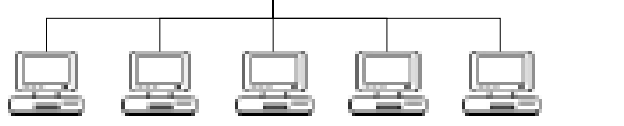

\section{LOGICOM system}

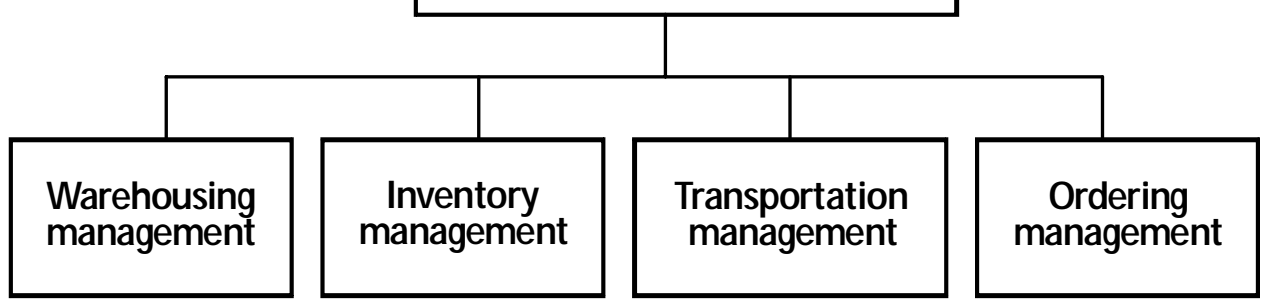


Figure 6. LLP system network for parts supply and inbound logisti

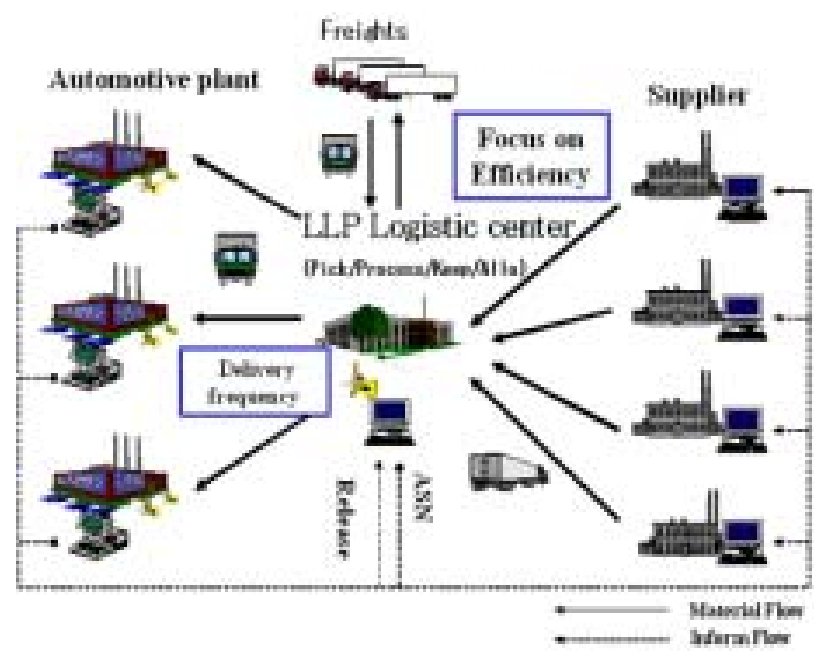

with parts suppliers is to eliminate excess parts inventory through JIT delivery. The following major process-reengineering efforts were conducted to enable logistics synchronization. First is the material requirement process driven by production scheduling of Ford Taiwan. The LOGICOM system served as a centralized network to collaborate material requirements between Ford Taiwan and its suppliers. Second is the SMF process enabling more frequent deliveries and smaller delivery quantities. Ford Taiwan suppliers deliver parts to its warehouse on a daily or weekly basis to replenish the stock. Based on the material requirement forecast and daily ASNs, McTI Taiwan schedules pickups from suppliers to its centralized logistical center and dispatches multiple parts distribution to Ford Taiwan's production line as if the parts were pulled from Ford Taiwan's own warehouse. The LLP system was officially launched in December 2005 with a pilot run on Ford Taiwan Southern area's key 15 suppliers. According to the supplier's location and parts characteristics, there are five delivery routes identified shown as Figure 7. McTI Taiwan coordinated part distributions to assembly plants based on the material forecast through the LOGICOM system.

An example to illustrate the LLP operation process is by using one route for the delivery routing. In route-5, there are three suppliers of cars wiring in Ping-Tung county (YAZAKI, ANTEC, and SHANG-

Figure 7. Delivery routes

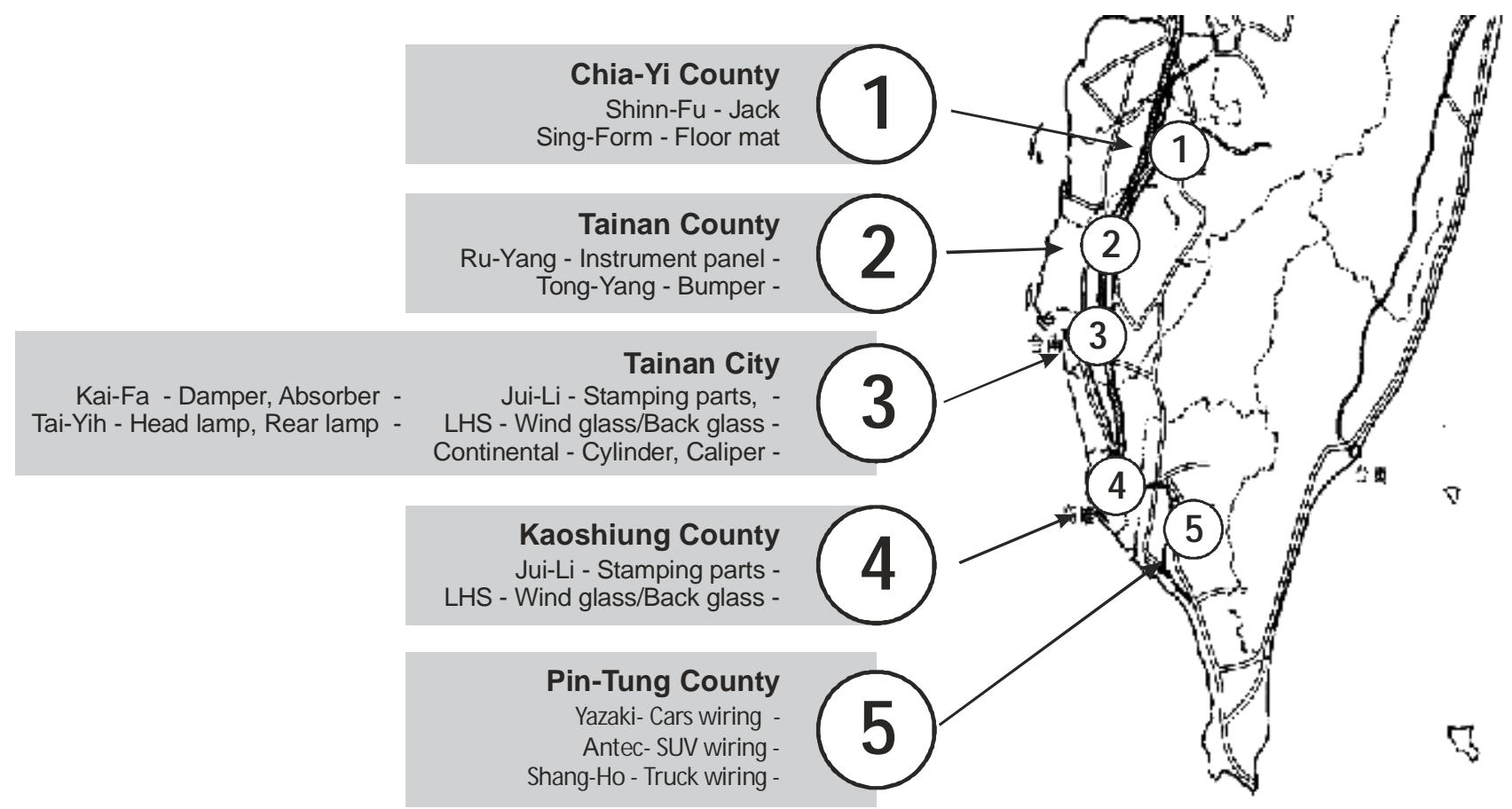


Figure 8. Milk-Run Process

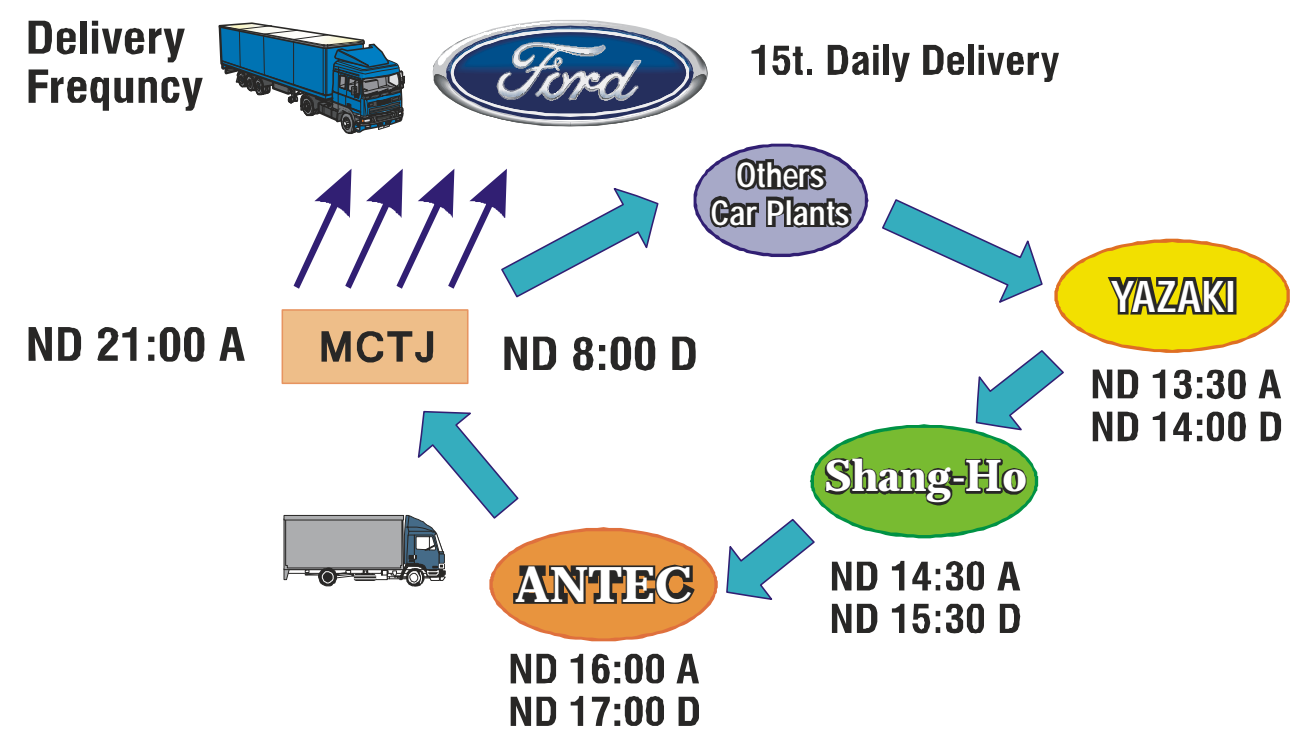

$\mathrm{HO})$, whose components of the cars wiring are delivered through LLP system executing a Milk-Run process. The Milk-Run process can be seen in Figure 8:

The assessment phase was set for 12 months starting from December 2005 to November 2006. A review meeting between Ford Taiwan and McTI Taiwan was conducted in December 2006. The performance measures identified by the LLP project were the inventory and transportation costs. The data collected from the 12-month assessment period showed a $22 \%$ savings in inventory costs and a $7.5 \%$ reduction in transportation costs. The inventory cost reduction was mainly due to LLP system logistics synchronization implementation in which Ford Taiwan and its suppliers no longer needed to maintain an excess parts inventory. Moreover, the McTI Taiwan owned and operated a fleet of trucks to drive down the transportation costs using freight consolidation. The other benefits reported include warehouse space saving, warehouses operating labor cost reductions, improved delivery performance, and quick response of stock replenishment.

Assuming the role of overall logistics management, McTI Taiwan moved one step further from supply chain coordination to logistics execution. With integrated LOGICOM system and transportation network, McTI Taiwan was able to plan and implement optimized distribution routes on a daily basis. Both Ford Taiwan and its suppliers were provided with shipping tracking information and tracing requests to resolve delivery exceptions. In case of a production exception, McTI Taiwan would trigger a contingency plan to collaboratively fulfill material requirements with the part suppliers. The initial success in the assessment phase was recognized by Ford Taiwan's executives; this then followed a decision for a full-scale LLP system deployment to its whole automotive supply chain.

\section{Discussion}

In this case study, we denote three major success factors in the development of the LLP system in the automotive supply chain industry. First, comprehensive information system integration provided a platform to share information on real-time basis. Apart from LOGICOM system, a wellestablished IT infrastructure and enterprise resource planning system from suppliers also contributed to the success of the IT integration. Second, an effective communication among the LLP, suppliers, and automotive plants laid the foundation of supply chain collaboration to manage logistics operations. And lastly, a continual business advancement and support from executive management drove the success of two major process re-engineering efforts. Furthermore, the LLP case provides several insights to be considered: 
- Selecting a right LLP - Selecting a capable LLP vendor to form logistics alliance is the most critical step in developing a LPP project. McTI possess an extensive lead logistics management knowledge and experience in the automotive supply chain. Moreover, McTI Taiwan built business partnership with Ford Taiwan to manage an effective supply chain. These can be considered as one of the most powerful marketing campaigns to expand its domestic market in Taiwan.

- Using a proven logistics system - The business decision of using software packages, such as in this study the LOGICOM system, had allowed cross-organizational process re-engineering leading to process alignment across the supply chain. Adapting the system had helped to minimize the system development time.

- Applying SMF process - Logistics synchronization implementation is an operational innovation that helps reduce the overall supply chain inventory. A prerequisite to the LLP project was a change in the distribution approach that would not affect a production schedule due to a material supply shortage. The JIT material distribution was implemented using more frequent deliveries in smaller quantities within a specified time window.

\section{Conclusion}

Strategic alliances are based on mutual benefits to all players working collaboratively to share profits and undertake the risks. A supply chain alliance is a single-source logistical outsourcing strategy between firms and their logistics provider and its development leads to moving from the 3PL to the LLP that plays the logistics management role in coordinating the 3PL and other logistics service providers. Successful application of such alliances, particularly the LLP, brings significant logistics savings to the entire supply chain.

A LLP system framework and LLP solution model were introduced in this study. The LLP system is composed of three components namely the Resource Management, Information Central System and Logistics Synchronization. This study presents a five-progressive step or phase in carrying out an effective LLP project which is the Plan, Design,
Contract, Implement and Assessment. A Taiwanese automotive supply chain case, Ford Taiwan and McTI Taiwan, was presented to illustrate the effectiveness of LLP system wherein its application resulted to a savings of $72 \%$ on its inventory costs and reduction of $7.5 \%$ on its transportation costs.

In conclusion, the LLP system is an effective supply chain alliance that enhances the competitiveness of entire supply chain by reducing logistics costs and improving logistics flexibility. The critical successful factors derived from this case include information integration, effective communication mechanism, and executive management support. Several observations were identified from the case wherein selecting the right LLP vendor was considered as the most critical decision-making as well as the adaption of a proven logistical system applying the SMF process. The findings in this study offer valuable insights to other industries as well as provide guidance towards implementing a LLP system in their respective supply chain industry.

\section{References}

Andel, T. (1995), There's power in number. Transportation $\mathcal{E}$ Distribution, Vol. 36, pp. 67-72.

Armbruster, W. (2002). 4PL, JoC Week, June 24-30.

Bask, A.H. (2001), Relationships among TPL providers and members of supply chains - a strategic perspective. The Journal of Business E Industrial Marketing, 16(6), 470-486.

Bhatnagar, R. and Viswanathan, S. (2000), Re-engineering global supply chains alliances between manufacturing firms and global logistics service providers. International Journal of Physical Distribution $\mathcal{E}$ Logistics Management, 30(1), 13-26.

Bolumole, Y.A. (2001), The supply chain role of third-party logistics providers. International Journal of Logistics Management, 12(2), 87-102.

Bowman, R., A High Wire Act. Distribution, Vol. 94, pp. 36-39.

Coyle, J.J., Bardi, E.J., and Langley, C.J. (1996), The Management of Business Logistics, 6th ed. West Publishing Co., St Paul, MN.

Ford Production system (2005), SMF version 4.6, May, h t t p : / / w w w. f p s.ford.co m / d o c s / elementbooksscoringtoolselementbooks.html.

Hoek, R.I. (2000), Role of third party logistic services in customization through postponement. International Journal of Physical Distribution \& Logistics Management, 31(6), 463-468. 
Hoek, R.I. and Chong, I. (2001), Epilogue: UPS Logistics practical approaches to the e-supply chain. International Journal of Service Industry Management, 11(4), 374-381.

Holweg, M. and Miemczyk, J. (2002), Logistics in the "three-day car" age: assessing the responsiveness of vehicle distribution logistics in the UK. International Journal of Physical Distribution \& Logistics Management, 32(10), 829-850.

$\mathrm{Hu}, \mathrm{H} . \mathrm{D}$. and Huang, J.D. (2008), Automotive industry supply chain selection model using FANP-GP and De Novo programming methodology. Proceeding of the second international conference on Operations and Supply Chain Management, Taipei, Taiwan, 301-309.

Lewis, J. (1990), Partnerships for Profit, Free Press.

Logicom (2004), Logistics system with future strategies, April, http://www.net-logicom.co.jp/english/ Lgsystem.htm.

McTI (2005), Strategic Logistics solution for Ford Lio-Ho Motor Company and its Suppliers, McTI Business Proposal for LLP Solution.

McTI (2004), Solution providing, April, http:// www.mcti.co.jp/eng/solution/index.html.

Ryder (2004), Visteon is making is making a name for itself, April, http://ryder.ed4.net/minisite2/mini/Articles / edge2_article5.htm.
Schwartz, E. (2003), The logistics handoff, Inforworld, 25(44) 53-58.

Simhan, R.T.E. (2003), 4PL logistics providers: scaling up supply chain efficiency, Businessline, June 23, p.1.

Vector (2004), Vector Supply Chain Management, April, http://www.cnf.com/vectorscm.asp.

Volvo (2004), Strategic solution: lead logistics provider, April,

http://www.volvo.com /logistics /na /en-us / strategic+solutions/ead+logistics+provider/LLP

tservices.htm.

Williams, L.R., Esper, T.L., and Ozment, J. (2002), The electronic supply chain: its impact on the current and future structure of strategic alliances, partnerships and logistics leadership. International Journal of Physical Distribution E Logistics Management, 32(8), 703-719.

Whipple, J.M. (2000), Strategic alliance success factors. Journal of Supply Chain Management, 36(3), 21-28.

Xiao, H., Yang, Y, Li, H, and Tang, X. (2009), Knowledgebased Logistics System of 3PL in P.R. China. International conference on Management and Service Science, Wuhan, China , 1-4.

Jheng-Dan Huang is currently a Ph.D. Candidate in the Department of Industrial Engineering and Management at Yuan Ze University, Taiwan. His research interests include Logistics System, Supply Chain Management, Computerized Facility Planning, and Lean Manufacturing System.

Michael H. Hu is an Associate Professor in the Department of Industrial Engineering and Management at Yuan Ze University, Taiwan. He received his Ph.D. degree in Industrial Engineering and Management from the Iowa State University, USA. His research interests include Logistics System, Supply Chain Management, Computerized Facility Planning, and Engineering Economic Analysis.

Hui-Ming Wee is a Professor in Department of Industrial and Systems Engineering at Chung Yuan Christian University in Taiwan. He received his BSc (Hons) in Electrical and Electronic Engineering from Strathclyde University (UK), MEng in Ind ustrial Engineering and Management from Asian Institute of Technology (AIT) and PhD in Industrial Engineering from Cleveland State University, Ohio (USA). His research interests are in the field of production/inventory control, optimization and supply chain management. His publications include four books and over 200 refereed journal papers. Further details can be found at http:// scrlab.twbbs.org/other.php 